\title{
Growth performance of three genotypes of ducks in coastal region of Bangladesh
}

\author{
MA I slam, MJ Khan, MR Debi* and MM Rahman
}

Department of Animal Nutrition, Bangladesh Agricultural University, Mymensingh 2202, Bangladesh

\begin{abstract}
A study was conducted to determine the growth performance and mortality rate of Khaki Campell, Jinding and Deshi genotypes in two coastal locations of Barisal and Bhola districts of Bangladesh. Sixty-day-old ducks of 3 genotypes were randomly allocated to 3 treatments having 4 replications in each. Ducks are reared up to 150 days and at the end of experiment one male Khaki Campbell of highest live weight was selected from each replicate group. The average weekly body weight gain ( $g /$ bird) of the Khaki Campbell and J inding were significantly $(p<0.01)$ higher than those of the Deshi ducks. The average body weight of Khaki Campbell (1480.25g) was slightly higher than that of Jinding $(1428.25 \mathrm{~g})$ but significantly $(p<0.01)$ higher than that of Deshi $(1140.62 \mathrm{~g})$ ducks at the end of the experiment. The mortality rate were significantly different $(p<0.01)$ in various genotypes. The highest mortality was found in Deshi (30.20\%) compared to Khaki Campbell (19.79\%) and Jinding $(17.77 \%)$. The profit margin was significantly different $(p<0.01)$ in three genotypes. The ducks reared in Barishal performed better $(p<0.01)$ than that from Bhola. It may be suggested from the present findings that both Khaki Campbell and Jinding ducks are performed better than Deshi in the coastal region of Bangladesh.
\end{abstract}

Key words: Growth performance, duck, growth, mortality and profit margin

Bangladesh Animal Husbandry Association. All rights reserved.

Bang. J. Anim. Sci. 2012. 41 (1): 19-23

\section{I ntroduction}

Duck rearing is an integral part of poultry husbandry. Poultry meat and egg play an important role in human nutrition throughout the world. Duck population of Bangladesh is estimated to be 35.53 millions (DLS, 2003) of which $95 \%$ are of indigenous type (Haque et al. 2003). The climate and environment of Bangladesh are suitable for duck habitation and the innumerable water bodies are also favorable for duck production. Duck production plays an important role in the southern coastal districts of Bangladesh, providing meat and egg and generates income. Bangladesh is a riverine country where $16488 \mathrm{Km}^{2}$ are haors, canals, pond and low-lying water reservoir and can be efficiently utilized for duck production. In Bangladesh most of the duck are indigenous (Ahmed 1986; Arboleda 1990) but other most important ducks available in the country are Khaki Campbell, Indian Runner, Jinding, Pekin and their crosses. Local ducks are ubiquitous in the country and most smallholder farmers keep them under subsistence level of management. The villagers who cannot afford to rear cattle or goat can easily maintain small number of poultry. Duck meat and eggs are thus the cheapest protein food among animal protein sources available in Bangladesh. Ducks have a great role in village poultry production (Farrell and Stapleton, 1986). About $89 \%$ of rural livestock households rear poultry (Islam et al. 2003). Consumption of duck meat and eggs in the country is estimated about 30 percent of total poultry meat and egg consumption (Islam el al. 2003). In coastal region of Barisal and Bhola, peoples are traditionally rearing indigenous non-descriptive ducks. Now-a-days, Jinding and Khaki Campbell ducks are getting popularity to the farmers of these areas. No comparative study on productivity, acclimatization ability and ability to disease resistance of Khaki Campbell and Jinding with indigenous ducks were done in coastal environments. Therefore, the present study was conducted in two southern districts of Bangladesh (Barisal and Bhola) to know the growth performance and mortality rate of three different genotypes (Khaki Campbell, Jinding and Deshi) of ducks and recommend a suitable genotype for the coastal region of Bangladesh. 


\section{Performance of duck in costal region}

\section{Materials and Methods}

In order to obtain a suitable meat purpose duck in the farm level, the experiment was conducted with a total of 288, sixty-day-old ducks belonging to three genotypes of Khaki Campbell, Jinding, and Deshi in two villages under two districts namely Barisal (144 Nos.) and Bhola (144 Nos.) having total 96 ducks for each genotype for a period of 5 months between December, 2009 to April, 2010. Twenty four farmers were selected from two locations having twelve farmers from each location. Each farmer was given 12 birds from any three (Khaki Campbell, Jinding and Deshi) genotypes of duck randomly. The experiment was conducted following Completely Randomized Design (CRD) having 4 replicates (families) for each genotype of Khaki Campbell, $J$ inding and Deshi. The experimental ducks were reared under the existing husbandry practices in the village. Supplemental feeds were offered to each duck with $40 \mathrm{~g}$ feed for 2 nd to $3 \mathrm{rd}$ months, $50 \mathrm{~g}$ for $4^{\text {th }}$ to $5^{\text {th }}$ months and $60 \mathrm{~g}$ for last month in the form of concentrate mixture composed of $30 \%$ broken rice, $30 \%$ crushed maize, $25 \%$ rice polish and $15 \%$ wheat bran; divided into two equal portions and were given twice daily. Feeds available in the study area were collected to know its availability and nutrient content. For this purpose, available feed such as rice polish, whole paddy, rice, broken rice, boiled rice, wheat and wheat bran are collected in every month and processed and analyzed in the Animal Nutrition Laboratory. The body weight of individual bird was measured at the end of each week during the experimental period of 150 days. Mortality of the birds, if any, was recorded group wise.

All ducks were vaccinated against duck plague and duck cholera as per the schedule. All the birds were kept in close observation at the age from five months to know the sexual maturity by observing the body characteristics and the mating tendency of male and female ducks and by the first lay of eggs. At the end of experiment, one male duck of highest live weight was selected from each replicate group in the morning before feeding. Data were subjected to analysis of variance in accordance with the procedure of completely randomized design. Significant differences were identified by Duncans new multiple range test. Mortality occurred in different treatment groups were analyzed by Chi square test.

\section{Results and Discussion}

\section{Growth performance}

The average initial body weights of the ducks of each genotype in two districts along with their weekly average body weight from 60 to 150 days are presented in Table 1 . It can be seen from the Table that live weights of the experimental ducks were differed significantly $(p<0.01)$ by different genotypes. The final body weight of the ducks at 150 days of age differed significantly $(p<0.01)$ among the different genotypes. The weekly individual body weight of ducks of each genotype throughout the experimental period was linearly increased in all groups. In each week the differences in body weight among the treatments were significant $(p<0.01)$. The final body weights of the Khaki Campbell ducks in Barisal and Bhola were higher than that of Jinding and Deshi genotypes (Table 1) and the final body weights of the Khaki Cambell ducks in Barishal were higher than that of Khaki Campbell in Bhola (Table 1). The body weights of the Jinding ducklings were significantly $(p<0.01)$ higher than of Deshi genotypes, which might be due the genetic characteristics of duck breed. In the present study, final body weight of Khaki Campbell (1484.50g) ducks in Barisal at 150 days of age was slightly higher than that of Jinding $(1435.80 \mathrm{~g})$ and significantly higher than that of Deshi (1140.62 g) genotypes. Both the values were lower than that of Zhang et al. (1989). Similarly final body weights of Khaki Campbell ducklings in Bhola (1476.50g) at 150 days of age were slightly higher than that of Jinding (1414.50g) and Deshi (1139g) genotypes. In a study Zhang et al. (1989) showed that body weight of Jinding duck at 150 days of age was $1500 \mathrm{~g}$, which was slightly higher than that of the present findings. The lower body weight of ducks in the present experiment might be due to lower feed availability of birds from scavenging. The final average body weights of Khaki Campbell duckss (1480.25g) at 150 days of age were slightly higher than that of Men et al. (1995) and Zhang et al. (1989). This variation may be because of the management system. 
Table 1. Weekly body weight ( $\mathrm{g}$ ) of three genotypes of duck from 60 to 150 days of age in two coastal locations

\begin{tabular}{|c|c|c|c|c|c|c|}
\hline \multirow{2}{*}{$\begin{array}{c}\text { Age of duck } \\
\text { (days) }\end{array}$} & \multicolumn{3}{|c|}{ Barisal } & \multicolumn{3}{|c|}{ Bhola } \\
\hline & $\mathrm{KC}$ & J inding & Deshi & $\mathrm{KC}$ & Jinding & Deshi \\
\hline 60 & $492.25^{b}$ & $514.25^{\mathrm{a}}$ & $573.50^{a}$ & $491.75^{d}$ & $527.00^{b}$ & $588.00^{a}$ \\
\hline 67 & $519.30^{b}$ & $557.00^{\mathrm{ab}}$ & $593.00^{a}$ & $551.80^{b}$ & $582.00^{b}$ & $644.80^{a}$ \\
\hline 74 & $548.00^{b}$ & $602.00^{a}$ & $613.00^{a}$ & $617.00^{c}$ & $644.00^{b}$ & $701.00^{a}$ \\
\hline 81 & $584.00 \mathrm{~b}$ & $656.50^{a}$ & $658.30^{a}$ & $674.00^{c}$ & $701.80^{b}$ & $727.30^{a}$ \\
\hline 88 & $643.00^{\mathrm{b}}$ & $706.00^{a}$ & $703.00^{a}$ & $736.00^{\mathrm{b}}$ & $757.00^{a}$ & $759.00^{a}$ \\
\hline 95 & $709.50^{b}$ & $771.80^{\mathrm{a}}$ & $758.00^{d}$ & $797.80^{b}$ & $817.80^{a}$ & $806.50^{b}$ \\
\hline 102 & $775.30^{b}$ & $827.00^{a}$ & $812.00^{a}$ & $862.30^{\mathrm{ab}}$ & $875.50^{a}$ & $831.30^{\mathrm{b}}$ \\
\hline 109 & $831.00^{b}$ & $907.00^{a}$ & $864.00^{\mathrm{b}}$ & $951.00^{a}$ & $927.00^{b}$ & $869.0^{€}$ \\
\hline 116 & $907.00^{b}$ & $970.00^{a}$ & $915.00^{b}$ & $1028.00^{\mathrm{a}}$ & $987.00^{b}$ & $912.00^{c}$ \\
\hline 123 & $1061.00^{a}$ & $1041.00^{a}$ & $959.00^{b}$ & $1058.00^{a}$ & $1041.00^{a}$ & $956.00^{b}$ \\
\hline 130 & $1159.00^{a}$ & $1137.00^{a}$ & $994.50^{\mathrm{b}}$ & $1145.00^{a}$ & $1120.00^{\mathrm{ab}}$ & $1010.00^{b}$ \\
\hline 137 & $1259.00^{a}$ & $1233.00^{a}$ & $1049.00^{\mathrm{b}}$ & $1231.00^{a}$ & $1211.0^{\mathrm{a}}$ & $1039.00^{b}$ \\
\hline 144 & $1369.00^{a}$ & $1325.00^{a}$ & $1103.00^{\mathrm{b}}$ & $1328.00^{a}$ & $1314.00^{\mathrm{a}}$ & $1091.00^{\mathrm{b}}$ \\
\hline 150 & $1484.50^{a}$ & $1435.80^{a}$ & $1142.30^{b}$ & $1476.50^{a}$ & $1414.50^{\mathrm{b}}$ & $1139.00^{c}$ \\
\hline
\end{tabular}

Means with different superscripts in the same row within the same location differ significantly $(p<0.01)$

\section{Body weight gain}

The average weekly body weight gain of duck of each genotype in coastal region from 60 to 150 days of age is shown in Table 2 . The results showed that differences in body weight gains were statistically significant $(p>0.01)$ among the genotypes in different weeks. The highest body weight gain was observed (Table 2) at $13^{\text {th }}$ week for Khaki Campbell $(131.5 \mathrm{~g})$ and Jinding $(109.0 \mathrm{~g})$, which were higher than that of Deshi genotypes (43.87g). The weekly average body weight gain of Khaki Campbell was found higher than that of Jinding and Deshi genotype throughout the experimental period. Higher body weight gain was observed for Khaki Campbell than that of Jinding and Deshi genotype of ducks. This finding is almost similar with the works of Kamal (1993). During the experimental period the highest body weight gain was found in Khaki Campbell (988.25g/bird) followed by Jindding (907.88g/bird) and Deshi (559.87g/bird), which indicate the genetic merits of the genotypes.

\section{Mortality}

It is evident from the Table 4 that there were significant differences $(p<0.01)$ among the genotype with regards to mortality. During the experimental period a total 9 birds died from Khaki Campbell, 8 died from Jinding and 14 from Deshi genotype in Barisal (Table 3), which differed significantly $(p<0.01)$ among the treatment groups. On the other hand, 10 birds died from Khaki Cmapbell, 9 died from Jinding and 15 from Deshi genotype in Bhola (Table 3) and significant differences $(p<0.01)$ were observed. Mortality of duckling in respect of the genotype was 19 (19.79\%) for Khaki Campbell, $17(17.77 \%)$ for Jinding and $29(30.20 \%)$ for Deshi (Table 4). All ducks were given vaccination as per schedule but mortality was noticed for duck cholera, which may be due to vaccination failure and other environmental factors.

Table 2. Average (ignoring locations) weekly body weight gain $(\mathrm{g})$ of duck from 1 to 13 weeks of age

\begin{tabular}{cccc}
\hline Weeks & Khaki Campbell & Jinding & Deshi \\
\hline 1 & 43.50 & 48.87 & 38.12 \\
2 & $47.00^{\mathrm{b}}$ & $53.375^{\mathrm{a}}$ & $37.87^{\mathrm{c}}$ \\
3 & $46.50^{\mathrm{b}}$ & $56.25^{\mathrm{a}}$ & $36.00^{\mathrm{c}}$ \\
4 & $60.50^{\mathrm{a}}$ & $52.50^{\mathrm{b}}$ & $38.50^{\mathrm{c}}$ \\
5 & 64.12 & 63.12 & $61.00^{\mathrm{a}}$ \\
6 & $65.12^{\mathrm{a}}$ & $56.50^{\mathrm{d}}$ & $39.37^{\mathrm{c}}$ \\
7 & $72.00^{\mathrm{a}}$ & $65.75^{\mathrm{b}}$ & $44.87^{\mathrm{c}}$ \\
8 & $76.62^{\mathrm{a}}$ & $61.25^{\mathrm{b}}$ & $47.25^{\mathrm{c}}$ \\
9 & $91.87^{\mathrm{a}}$ & $62.87^{\mathrm{d}}$ & $43.87^{\mathrm{c}}$ \\
10 & $92.50^{\mathrm{a}}$ & $87.25^{\mathrm{b}}$ & $44.37^{\mathrm{c}}$ \\
11 & $92.75^{\mathrm{a}}$ & $93.37^{\mathrm{a}}$ & $42.25^{\mathrm{c}}$ \\
12 & $104.25^{\mathrm{a}}$ & $97.62^{\mathrm{b}}$ & $52.50^{\mathrm{c}}$ \\
13 & $131.50^{\mathrm{a}}$ & $109.12^{\mathrm{b}}$ & $43.87^{\mathrm{c}}$ \\
\hline
\end{tabular}

Means with different superscripts in a row differ significantly $(p<0.01)$ 


\section{Performance of duck in costal region}

Table 3. Mortality of ducklings during the experimental period in Barisal and Bhola

\begin{tabular}{llccc}
\hline Area & $\begin{array}{c}\text { Genotype } \\
\text { No. birds } \\
\text { at the } \\
\text { start }\end{array}$ & $\begin{array}{c}\text { Survival } \\
\text { at the } \\
\text { end }\end{array}$ & $\begin{array}{c}\text { Mortality } \\
(\%)\end{array}$ \\
\hline \multirow{4}{*}{ Barisal Jinding } & 48 & 39 & $18.75^{\mathrm{a}}$ \\
& KC & 48 & 40 & $16.67^{\mathrm{a}}$ \\
& Deshi & 48 & 34 & $29.17^{\mathrm{b}}$ \\
\hline \multirow{3}{*}{ Bhola } & KC & 48 & 38 & $20.84^{\mathrm{a}}$ \\
& Jinding & 48 & 39 & $18.75^{\mathrm{a}}$ \\
& Deshi & 48 & 33 & $31.25^{\mathrm{b}}$ \\
\hline
\end{tabular}

Mortality percentage with different superscript within the same region differed significantly $(P<0.01)$

Table 4. Mortality of ducklings during the experimental period in Barisal and Bhola

\begin{tabular}{lccc}
\hline Genotypes & $\begin{array}{l}\text { No. of birds } \\
\text { at the start }\end{array}$ & $\begin{array}{l}\text { Survival } \\
\text { at the } \\
\text { end }\end{array}$ & $\begin{array}{l}\text { Mortality } \\
(\%)\end{array}$ \\
\hline KC & 96 & 77 & $19.79^{\text {a }}$ \\
Jinding & 96 & 79 & $17.77^{\mathrm{a}}$ \\
Deshi & 96 & 69 & $30.2^{\mathrm{b}}$ \\
\hline
\end{tabular}

Mortality percentage with different superscript differed significantly $(P<0.01)$

\section{Economic analysis}

The expenditure for rearing Khaki Campbell, Jinding and Deshi ducks for growth for a period between 60 to 150 days and profit margin have been presented in Table 5 . There was a great variation in the present market price of the mature ducks, which was Tk. 250.00 per bird for both Khaki Campbell and Jinding and Tk. 200.00 per bird for Deshi, among three genotypes of ducks. Profit margin from 3 months was lowest (Tk. 39.10) in Deshi and the highest (Tk. 89.10) in Khaki Campbell and Jinding. Similarly, the percent profit margin (55.38\%) was found highest in Khaki Campbel and Jinding. Similar trend was found while calculating benefit cost ratio, which was 1.55 for Khaki Campbell and Jinding and 1.24 for Deshi ducks (Table 5). There was no variation in cost benefit ratio between Khaki Campbell and J inding but wide variation with Deshi ducks. The total income, profit margin and the percent profit margin of the ducks differed significantly $(P<0.01)$ between Deshi and the other two genotypes. There is no significant difference between two locations for total cost, total income, profit margin and the percent profit margin.

Table 5. Economic analyses of three genotypes of duck rearing in Barisal and Bhola from 60 to 150 ages of days

\begin{tabular}{|c|c|c|c|c|}
\hline \multirow{2}{*}{ Parameters } & \multicolumn{3}{|c|}{ Genotype } & \multirow{2}{*}{ Sig. leve } \\
\hline & KC & Jinding & Deshi & \\
\hline Expenditure & \multirow{2}{*}{100} & \multirow{2}{*}{100} & \multirow{2}{*}{100} & \multirow{2}{*}{ NS } \\
\hline Cost of duck (Tk/duck)* & & & & \\
\hline Feed cost* (BDT.)@ 12.8Tk/Kg & 58.40 & 58.40. & 58.40 & NS \\
\hline Medicine and vaccination* (Tk/duck) & 2.00 & 2.00 & 2.00 & NS \\
\hline Miscellaneous (Tk/duck) & 0.5 & 0.5 & 0.5 & NS \\
\hline Total cost (Tk./duck) & 160.9 & 160.9 & 160.9 & NS \\
\hline \multicolumn{5}{|l|}{ Income } \\
\hline Ducks price at the beginning of egg production ${ }^{* *}$ & $250.00^{a}$ & $250.00^{a}$ & $200.0^{\mathrm{b}}$ & $* *$ \\
\hline Profit margin (Tk/duck) & $89.10^{a}$ & $89.10^{a}$ & $39.10^{\mathrm{b}}$ & $* *$ \\
\hline Profit margin (\%) & $55.38^{a}$ & $55.38^{a}$ & $24.30^{b}$ & $* *$ \\
\hline Benefit cost ratio (BCR) & $1.55^{\mathrm{a}}$ & $1.55^{\mathrm{a}}$ & $1.24^{\mathrm{b}}$ & $* *$ \\
\hline
\end{tabular}

Means with different superscripts in a row differed significantly $(p<0.01)$; NS, non significant; *, The cost was considered at the market price in 2009; **, The selling price of ducks reported based on the local market in 2009 


\section{Conclusion}

Comparison to two locations ducks reared in Barisal showed better performance in terms of body weight, growth rate, and mortality. Khaki Campbell and Jinding ducks were found almost similar in growth rate and mortality. Considering the parameters studied both Khaki Campbell and Jinding ducks may be suggested to rear in the coastal region of Bangladesh in compare to Deshi duck.

\section{Acknowledgements}

The fund for the research work was provided by Palli Karma Sahayak Foundation (PKSF) Dhaka. The authors are gratefully acknowledge the receipt of the fund from the organization. The authors are also gratefull to the farmers of Barishal and Bhola Districts who directly involved with the rearing and management of ducks.

\section{References}

Ahmed S and Islam N (1986). Backyard Poultry Development Project in 100 villages, sponsored by Bang. Agril. Univ., Mymensingh and assisted by UNICEF, Bangladesh. Proc. $1^{\text {st }}$ Con. Bang. Anim. Husbandry Assoc., Bang. Agri. Res. Council, Dhaka. P. 133-138.

Arboleda CR (1990). Development of Duck Industry in Bangladesh. A discussion paper presented to selected government officers, at the Department of Livestock Services, Pashu Sampad Bhaban, Dhaka, October 30.

DLS (2003). Annual Progress Report. Department of Livestock Services. Farm gate, Dhaka.
Farrell DJ and Stapleton P (1986). Duck Production Science and World Practice. The University of New England, Armidale, NSW. P. 430

Huque KS and Sultana N. (2003). Organic Duck farming in Bangladesh and Entrepreneurship Development. Proceeding of $3^{\text {rd }}$ Int. Poultry Show and Seminar. Bangladesh China Friendship Conference Center, Dhaka, Bangladesh. P. 279-287.

Huque Q ME and Hossain MJ (1991). Production potentiality of ducks of three genotypes under scavenging system of management. Bangladesh Journal of Animal Science. 20 : 119-122.

Islam MN, Huque QME, Salah Uddin M and Sarker MSK (2003). Potentiality of Native Genotypes of Ducks. Proceedings of $3^{\text {rd }}$ International Poultry Show and Seminar, Bangladesh China Friendship Conference Center, Dhaka, Bangladesh. P. 259-270.

Kamal MM (1993). Study on the effect of supplementation of rice polish on the performance of Khaki Campbell Duck under village condition. M. Sc. Thesis. Department of Animal Nutrition, Bang. Agril. Univ., Mymensingh, Bangladesh.

Men BX, Ogle B and Preston TR (1995). Studies on duck production in the Mekong, Delta, Vietnam. Integrated Farming in Human Development-Proceedings of a Workshop, Cantho University, Vietnam.

Zhang S, Chen $Y$ and Lai $Y$ (1989). Jinding duck (a layer duck). Waterfowl production. Proceeding of the International Symposium on Waterfowl Production, the Satellite Conference for the XVIII World's Poultry Congress, September 11-18, 1988; Beijing, China. P. 66-71. 